\title{
Research on Self-regulated Learning Platform based on Massive Micro-Lessons
}

\author{
Zhou DU, Xiaochun WANG*, Hui MA, Deming LIANG \\ Department of Educational Technology, Capital Normal University, Beijing, 100048, China \\ *Corresponding author
}

\begin{abstract}
The students' ability of self-regulated learning will affect their personal development in the future. Micro-lesson as a new video resource provides more suitable form for self-regulated learning. At present, the existing micro-lesson learning platform puts too much emphasis on resources, cannot completely provide students with independent learning support service. Therefore, this paper first analyzes the characteristics of self-regulated learning environment which should be, and then, designs the self-regulated learning platforms based on massive micro-lesson, and describe its learning process design, function design and architecture design in detail. Finally, the software prototype is developed. Practice shows that this platform can provide the good support for the self-regulated learning.
\end{abstract}

KEYWORD: Massive Micro-lesson; Self-regulated learning; Platform design

\section{INTRODUCTION}

Self-regulated learning is very important for students' individual development and lifelong learning [1], whose form is constantly evolving with the advancement of technology. From 2010 to the present, micro-lesson had a spurt of development. Micro-lesson has the clear teaching objective, dapper content, and focus on solving a certain problem. Its features such as simplicity, pragmatism, diversification, entertaining, make them more appropriate for the sharing and dissemination based on the network platform [2]. With the development of micro-lessons, its quantity has become the massive, and its range of knowledge is more extensive and flexible, so that the teachers with different teaching styles could provide more choices for students. In recent years, micro-lesson is becoming massive in quantity, more extensive and flexible in content, different in difficulty degrees and teaching styles, which could provide personal, autonomous and effective resources for every citizen under the background of learning society and lifelong education [3]. For students, micro-lesson is a kind of effective supplementary resources outside the classroom [4], and provides the guarantee for the realization of students' individualized learning. Learners can choose micro lesson with different depths according to the degree of their own learning. However, facing so many micro-lessons, how to let the students with different learning ability quickly and efficiently find micro-lesson they needed?
Current research in self-regulated learning platform rarely involves related platform design, and cannot fully meet the personalized needs of learners. Therefore, this paper design and implement a selfregulated learning platform based on massive microlessons.

\section{ANALYSIS OF SELF-REGULATED LEARNING PLATFORM CHARACTERISTICS}

There are mainly three stages in self-regulated learning: before learning activities, in the process of learning, and after learning. Before the activities, the goal needs to be determined, the learning plan needs to be developed, and specific learning preparations need to be done. During the learning activities, selfmonitoring, self feedback and self adjustment need to be done about learning progress and learning method. After the activities, self-examination, selfsummary, self-evaluation and self-recovery need to be done about the learning results [5]. In summary learners can adhere to self initiative learning and makes an evaluation on the self learning. With the rapid development of the Internet and cloud computing, the prevalence of social networks, independent study is promoted to show the new forms and characteristics under the influence of community doctrine and the maladjustment of students under the environment of the network learning [6]. According to the analysis of the characteristics for self-regulated learning, the 
massive micro-lessons learning platform should have the following five characteristics:

(1)Large-scale resources

With the arrival of the era of cloud learning, learning resources could be stored in different regions of the server, and massive micro-lessons have formed. These micro-lessons can provide resources for learning platform and satisfy the different learning needs.

\section{(2)Individuation}

With the support of new technology, every learner in the autonomous learning is no longer passively accepting the transfer of knowledge [7]. However, they take the initiative to search for resources, establish resources and release information during the interaction on the basis of their own learning. All learners' online behavioral activities could be recorded through the study of analytical technique, and thus the portfolio of learning process is formed. It is convenient for every learner to build individual learning pass and repository, and to provide support for the learners' personalized learning.

\section{(3)Interactivity}

With the rapid development of the Internet and the popularization of the mobile terminal, the learnerlearner interaction, learner-teacher interaction and learner-resource interaction are becoming more and more frequent. In the learning process, the support of methods with strong interactive features, such as live chat, synchronized video and notes-taking, makes it convenient for learners to disseminate and share knowledge with teachers or other learners whenever possible.

\section{(4)Resource diversity}

The resource diversity is essential to meet the learners' different learning styles and characteristics of the learner [8]. Different micro-lesson design styles, teaching styles, teaching activities and evaluation provide learners with a diverse choice.

\section{(5)Learning situations}

Learner's location, time, and surroundings are the related elements of the situation. This platform supports mobile terminals, and provides the most convenient learning support according to the specific situation of the students. For example, when the learner is in a poor local network status, the platform would provide offline viewing capabilities. It can shorten the time the learner can find resources, strengthen learners' learning motivation.

\section{THE DESIGN OF SELF-REGULATED LEARNING PLATFORM BASED ON MASSIVE MICRO-LESSONS}

Based on the above analysis, self-regulated learning platform is designed from the following three aspects.

\subsection{Learning process design}

Because of different construction of knowledge for each student, personalized need is more highlighted about their desires for learning content or theme in network learning. System can help learners find the related micro-lessons according to the learner's personalized characteristic and thus reduce the redundant steps in learning, as shown in Figure 1.

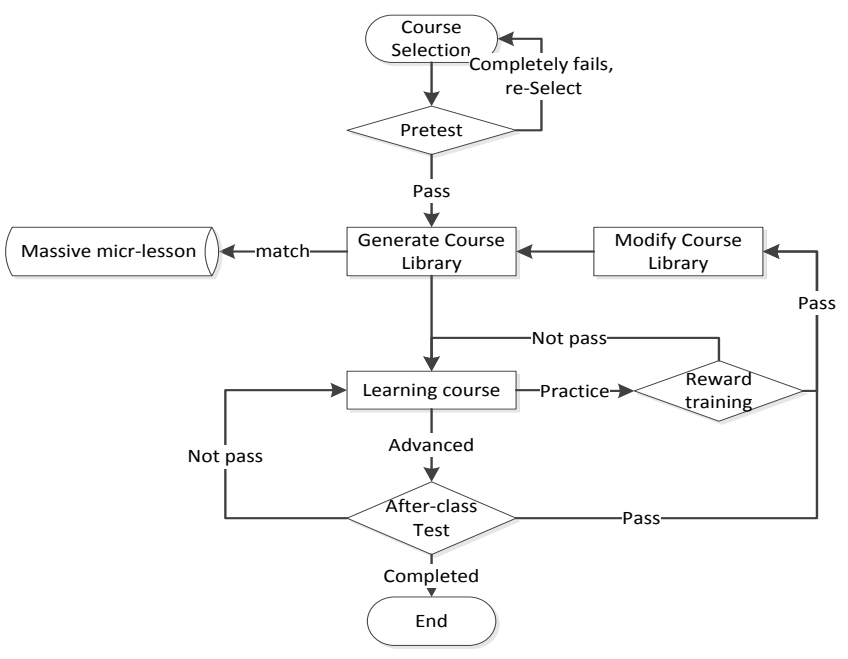

Figure 1. Learning process design.

This platform's solution is in front of independent learning, for students to do small test, forming the students' individual knowledge library. Students are free to choose the micro-lesson to learn. After the completion of learning, students can be carried out after-class test. After the test is completed, the platform will modify the student knowledge tower. At the same time, the platform matches the related micro-lessons according to the students' knowledge tower and student preferences. Students can choose among the micro-lesson in the recommended curriculum for learning or their own re-select a new curriculum for learning. As students continue to learn, test, knowledge tower will be gradually increased continuously generated, students can view themselves' knowledge tower and according to these records to determine next steps in learning.

\subsection{The function of the platform design}

The self-regulated learning platform consists of five modules including micro-lessons resource, question answering system, backstage management, learning and tracking system and retrieval system. The specific function of the structure is as shown in Figure 2.

1) Micro-lesson resource is the core of this platform, the module is provided from the production and editing, perfect editing, publishing, secondary changes, organize a test and a series of functions for the teacher. Students can download the micro-lesson and evaluate it. 


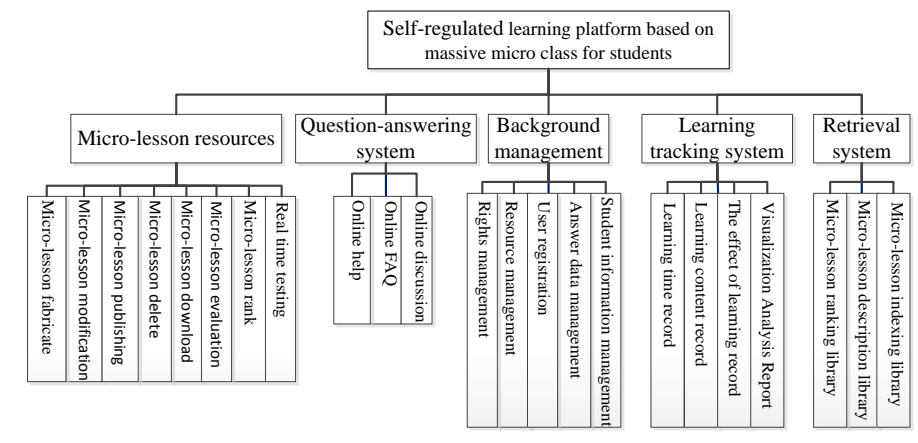

Figure 2. Platform function structure.

2) Question-answering system supports students to ask questions about knowledge points in the micro-lesson. It's convenient for the teacher to locate specific questions and to answer, as well as to communicate with students. Online discussion provides a community for learners to discuss with other learners. In the course of discussion, the learners could upload and download the related materials for study.

3) The background management is mainly in charge of platform resources, online FAQ, user registration and rights management. After the teacher edited micro-lessons using offline version, the system would autonomously synchronize the micro-lesson to the cloud server in the background.

4) With xAPI technical specifications, learning tracking system separate the learning content from platform, which can record and provide metadata related to the learners, including the learning time, learning progress, interaction and learning process, etc, and thus make the formation of the learner's portfolio of learning process. It is convenient for teachers and students to analyze the learning process from various angles, and give a variety of visualization charts, for example: knowledge points list, online learning time statistics, etc.

5) Micro-lesson description, indexing and ranking from the retrieval system provide the basis for students' retrieving relevant micro-lesson, which help teachers and students to have access to microlessons of high quality.

\subsection{Architecture design}

The platform is built on cloud services. Users can take full advantage of the platform for learning resources to meet the needs of students in independent study. Learners not only can have access to resources on the platform, but also take advantage of the platform to upload and share resources, so that the cycle forms (as shown in Figure 3).

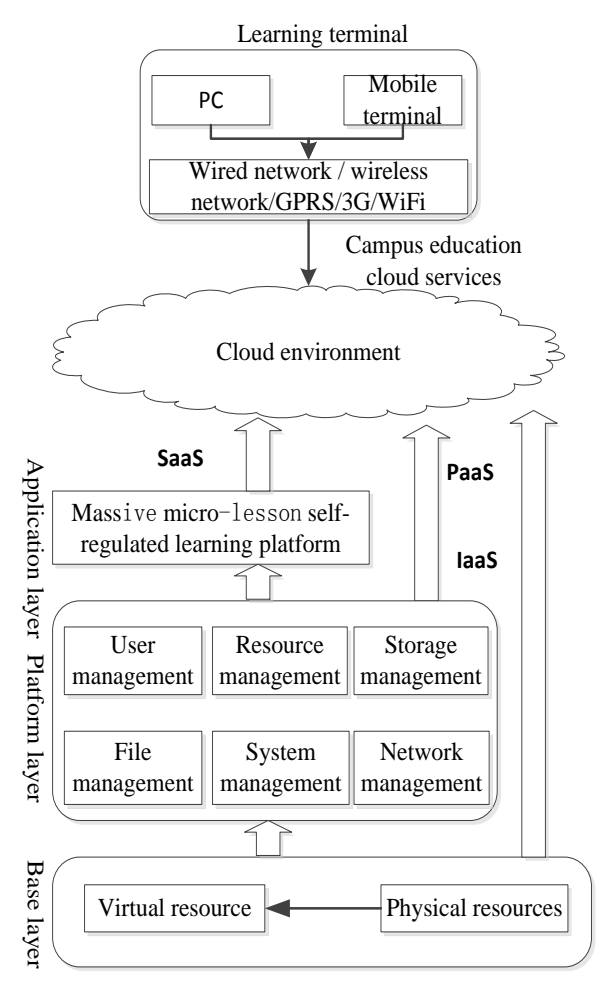

Figure 3. Architecture structure for self-regulated platform.

The learning-terminal the platform support include the existing PC terminal and a variety of mobile terminal equipment. Learners use the Internet, wireless network, GPRS, 3G to visit campus education cloud services platform so as to get the corresponding learning resources and learning services.

Campus cloud service is using the campus hardware and massive cloud micro-class resources. We will publish the micro-lesson to meet student's need and stored it into cloud, while recording data of students. Using the server of campus cloud platform and network analytic service, the resources are created and shared, and the teaching cost is lessened.

This platform emphasized the sharing of resources and allocating as needed, which is usually divided into three levels. The bottom level is dynamic cloud infrastructure services (IaaS), composed of hardware or virtual machine resources, through the virtual resource pool to each according to his need for the school network, servers, storage, applications, etc, which is the foundation of service system. The second layer is the online development platform layer (PaaS), which provides massive file system, massive database system, mass message system services through distributed computing and storage environment. Through online development platform, massive micro-lesson autonomous learning platform construction provides the interface with the environment, operating system, application development environment platform web products to provide services for the teachers and students. It's convenient for teachers and students to develop teaching resources. The third layer is the resource application service layer (SaaS), which is the 
interface between the user and the cloud service system, providing the self-regulated learning platform services directly to the teachers and students in the Universities. University teachers and students can use the Personal Computer, mobile phone or other mobile terminal device to have access to the cloud side and enjoy the service platform at any time, any place.

\section{IMPLEMENTATION OF SELF-REGULATED LEARNING PLATFORM}

Based on Cloud information technology, it is an open self-regulated learning platform for learners to interact with each other and share the information with others, no matter when it is and where you are, via different terminals. The implement of selfregulated learning platform included cloud storage, personal knowledge base and student management.

\section{(1) Cloud storage}

Self-regulated learning platform adopt the incremental data backup method to backup student registration information to avoid the loss of registration information. For micro-lesson, microlesson description redundant storage method was applied, on the one hand, to avoid data loss, on the other hand, to provide load balancing for frequent data access. Therefore this project intends to use Hadoop storage scheme. Hadoop system can detect and monitor changes in storage capacity of the whole distributed storage system and hard disk damage so as to extend the storage system, unplug the damaged storage devices, and recover data through redundancy recovery algorithms.

\section{(2)Personal knowledge base}

Through resource statistics, the base classified resources into video, files, documents, etc. according to students' use and collection. Collection of resources by students can be previewed, downloaded and viewed online. At the same time, the latest course and course with high collection rate will be displayed for students.

\section{(3)Student management}

Student management functions contain delete, edit, forbidden, start using, reset the password for students; fuzzy search can be implemented according to user's name, position, name, school, grade, subject.

The platform has been applied at Shunyi District in Beijing. Students are able to find what they need in the massive resources in a fast and high efficient way. Game mechanics can stimulate students' learning passions; provide a self-learning environment for students to improve students' selfregulated learning effect by supporting massive resources through interactive ways, and recording the whole course.

\section{CONCLUSION}

Self-regulated learning is a basic skill that students should have with their self-development. Microlesson, as a new form of learning resources, provides more resources in line with self-regulated resources. Massive micro-lessons have provided more choices for each learner. Taking the new learning support services into consideration, such as the cloud storage, cloud computing, analysis technology, the thesis tries to make an analysis of the characteristics of the learners more objectively by carrying on the design and research on students' learning process, platform resources and game mechanics. The platform has been applied in Shunyi District, the result of which shows that great improvement has been achieved in the effect of students' selfregulated learning.

\section{ACKNOWLEDGMENTS}

The research is supported by Science and Technology Plan of Beijing Municipal Education Commission under Grant No. KM201410028018, and also supported by Planning of the National Education Science under Grant No.DCA120189.

\section{REFERENCES}

[1] Garrison, D.R. 1997. Self-directed learning: Toward a comprehensive model, Adult Education Quarterly (48): 118.

[2] Zhou Yan \& Li Yuze \& Xu Yidong. 2014. Based on the concept of MOOC micro course resources website design, Modern education technology, 113-118.

[3] Hu Tiesheng \& Huang Mingyan \& Li Min, 2013, The three stages of the development of China's micro class and its enlightenment, Journal of distance education, 36-42.

[4] Yu Shengquan \& Wan Hai-peng, 2014, support large-scale open learning courses, China audio-visual educational, 718.

[5] Pang WeiGuo, 2003, Autonomous learning: learning and teaching theory and strategy, East China normal university press, Shanghai, 5.

[6] Zhao Hong \& Chen Li, 2012, Distance learners' autonomous learning ability training method research, Journal of electrochemical education research, 56-63.

[7] Barbara B. Seels \& Rita C. Richey, 1994, Instructional Technology: The Definition and Domains of the Field, Central Radio and Television University Press; Bloomington.

[8] Yu Shengquan \& Chen Min, 2014, Micro class design based on Meta micro course learning platform, Open education research, 100-110. 